\title{
The Relation Between Critical Velocity and the Collision Ship Tonnage
}

\author{
Wu Wen-feng \\ School of Maritime and Civil Engineering of ZJOU \\ ZheJiang Ocean University \\ ZhouShan, China \\ Wuwenfeng0611@126.com
}

Lu Jin-shu

1 School of Maritime and Civil Engineering of ZJOU

ZheJiang Ocean University

ZhouShan, China

goldtree_lu@163.com

\author{
Wen Xiao-fei \\ School of Maritime and Civil Engineering of ZJOU \\ ZheJiang Ocean University \\ ZhouShan, China \\ 183917760@qq.com \\ Zhu Gui-bing \\ School of Maritime and Civil Engineering of ZJOU \\ ZheJiang Ocean University \\ ZhouShan, China \\ 172631200@qq.com
}

\begin{abstract}
The bulb bow of bulk carrier and the double hull oil tanker are simulated. Based on the numerical software ANSYS/LS-DYNA, quantitative analysis was performed for these types of ship side collision. By the results of simulation, the critical velocities lead crack both on outer-plate and inner-plate of collided ship are obtained, by numerically analyzing the relations between the critical velocity and the tonnage of the collided ships, and the mathematical expressions are developed, which can provide suggesting for maritime management.
\end{abstract}

Keywords- ship collision; numerical simulation; ship tonnage; critical velocity; numerical analysis

\section{INTRODUCTION}

With the development of shipping, maritime traffic accidents often occurs. The ship collision has occupied a large proportion in the maritime traffic accidents, which is one of the important research field of shipping industry concerned, therefore many researchers were studied in the filed [1-7]. Ship collision will cause serious impact on marine environment. Study ship collision in order to improve the crash worthiness and reduce the consequences.

Double hull oil tanker outer or inner shell rupture is a serious failure caused by the ship collision. When processing of the simulation results revealed that there exists a critical velocity for the struck ship, if the striking ship collide the struck ship velocity exceeds the critical velocity, the struck ship's outer or inner shell will rupture. Therefore, determine the critical velocity of the striking ship is an important and meaningful research. Based on the numerical software ANSYS/LS-DYNA, quantitative analysis was performed for ship side collision, and to determine the cause of the relationship between the critical velocity and the ship tonnage according to the simulation results.

\section{SELECT TARGET SHIP TYPE}

According to the Ministry of Transportation's Maritime Administration of the ship accident statistics ${ }^{[8]}$, more than 100,000 -ton vessel encounter with the same tonnage and above-ton ship is less likely, the number of ship collision accidents are less. Taking into account the tanker was collide and leaked, the impact on the marine environment of the largest, and extensive bulk cargo ship tonnage distribution. Taken together, the paper selected the striking ship are the bulk cargo ship, and the struck ship are the double hull oil tanker. Meanwhile, according to the requirements of MARPOL Convention and China Classification Society Rules for Seagoing Steel Ships and other regulations, taking into account the modeling and simple calculations, checking the vertical actual ship data, based on the results of the selected summary ship's main dimensions and main parameters are shown in Table III.

\section{COLLISION SCHEMATIC AND FINITE ELEMENT MODELING}

Ship collision is an extremely complex nonlinear dynamic response process, and have many factors ${ }^{[9,10]}$. This article only demonstrates the influence of the tonnage on critical velocity, and assuming the striking ship that have a prominent bulb (other bow types will be studied in another paper) perpendicular to the collide the struck ship that is quiescent, and keep the impact position remain unchanged.

The striking ship adopt elastic-plastic material and sheet thickness consistent with reality, and set the internal components. To ensure the quality of the striking ship, the actual center of gravity is consistent with an increase in the rear side of the bow cabin quality as an accessory structure [11-14], by changing the quality of the attachment structure to change the ship's tonnage, the struck ship's plate thickness and other related components according to the actual structure and material properties. And ensure the struck ship's quality, consistent with the actual center of gravity, etc. Cabin structure using plastic dynamic model simulations. Finite element model shown in Figure 1.

According to relevant research, additional water quality could solution the effect between the ship body and the fluid. Using SHELL unit to simulate the ship collision, and the collide area mesh refinement, material model 
considering strain rate sensitivity of using CowperSymonds constitutive equation, failure strain is taken as $0.1^{[15,16]}$. Take the master-slave contact algorithm of structure involved in the collision, and the struck ship side structure is the definition of automatic single surface contact.

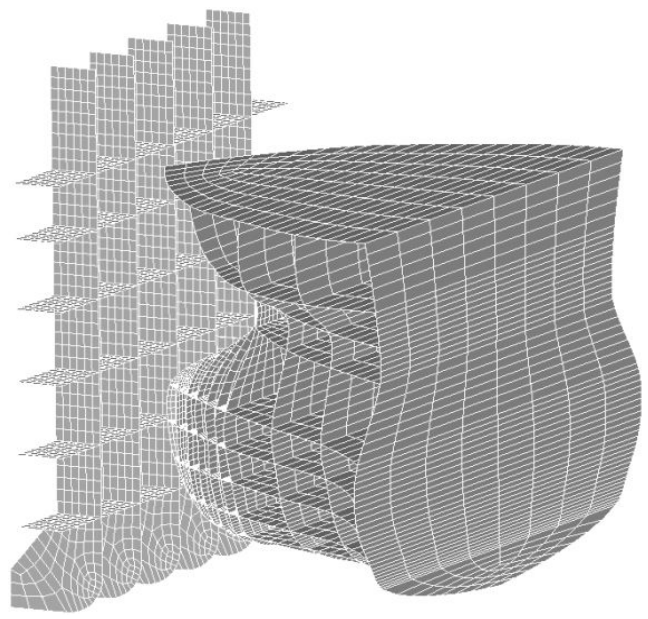

Figure 1. Finite element model of hull structure

\section{CALCUlation RESUlts}

\section{A. The relationship between critical velocity of outer} shell and tonnage of the striking ship

Figure 2 shows the relationship between critical velocity of outer shell and tonnage of the striking ship, and the striking ship adopt the same tonnage bulk cargo ship, while the struck ship adopt the different tonnage of double hull oil tankers. Using the logarithmic function form: $\mathrm{V}_{\text {outer }}=\mathrm{A} * \ln \mathrm{M}_{\text {struck }}+\mathrm{B}$, and the results shown in Table I .

TABLE I. SimULATION BETWEEN OUTER SHELL CRITICAL VELOCITY AND THE STRUCK SHIP TONNAGE

\begin{tabular}{cccc}
\hline Tonnage of striking ship & $\mathrm{A}$ & $\mathrm{B}$ & $\begin{array}{c}\text { correlation } \\
\text { coefficient }\end{array}$ \\
\hline 10000 & -1.32 & 21.54 & 0.987 \\
20000 & -1.3 & 19.32 & 0.994 \\
50000 & -1.31 & 18.51 & 0.957 \\
70000 & -1.28 & 17.93 & 0.972 \\
100000 & -1.3 & 17.85 & 0.973 \\
\hline
\end{tabular}

B. The relationship between critical velocity of outer shell and tonnage of the collision ship

On the table 1, we can see the parameter "A"has little relationship with $\mathrm{M}_{\text {struck, }}$, then take a mean of parameter "A" can obtain -1.302. Then refit the $\mathrm{V}_{\text {outer }}$ and $\mathrm{B}$, and can obtain the new parameters of a series of $\mathrm{C}$, see Table II .

TABLE II. TABLE 3 SIMULATION BETWEEN OUTER SHELL CRITICAL VELOCITY AND THE STRUCK SHIP TONNAGE

\begin{tabular}{cccc}
\hline Tonnage of struck ship & A & C & correlation coefficient \\
\hline 10000 & -1.302 & 21.32 & 0.9845 \\
20000 & -1.302 & 19.30 & 0.9826 \\
50000 & -1.302 & 18.38 & 0.9801 \\
70000 & -1.302 & 18.08 & 0.9923 \\
100000 & -1.302 & 17.83 & 0.9953 \\
\hline
\end{tabular}

Since the $V_{\text {outside }}$ must have some relation with the tonnage of striking ship ( $\left.\mathrm{M}_{\text {striking}}\right)$, and therefore the parameter $\mathrm{C}$ and the $\mathrm{M}_{\text {striking }}$ were fitted, shown in Figure 3, and the relationship between parameter $\mathrm{C}$ and $\mathrm{M}_{\text {striking }}$ can be expressed as follows:

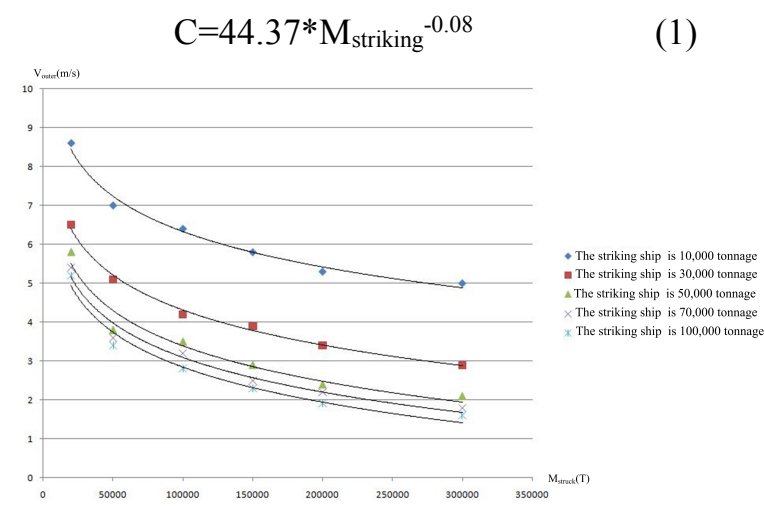

Figure 2. Curvilinear relation between $\mathrm{V}_{\text {outside }}$ and $\mathrm{M}_{\text {striking }}$

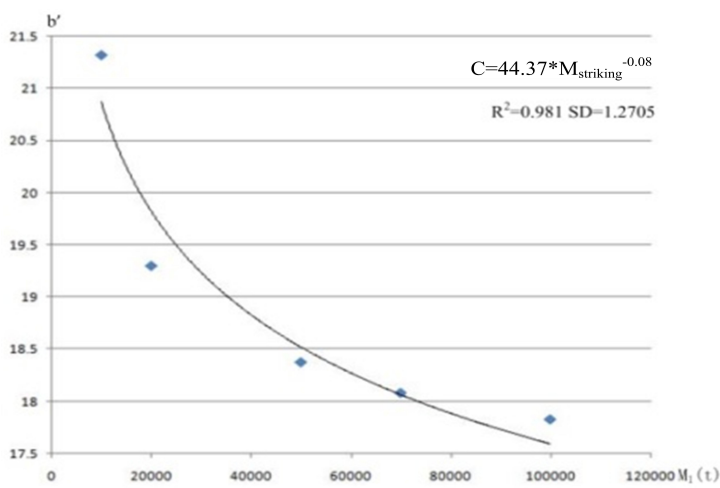

Figure 3. Curvilinear relation between $\mathrm{C}$ and the collision ship

In conclusion, the relationship between critical velocity of outer shell and tonnage of the collision ship can be expressed as:

$$
\mathrm{V}_{\text {outer }}=44.37 * \mathrm{M}_{\text {striking }}{ }^{-0.08}-1.302 * \ln \mathrm{M}_{\text {struck }}
$$

\section{The relationship between critical velocity of inner shell and tonnage of the collision ship}

The relationship between critical velocity of inner shell and tonnage of the collision ship is shown in Figure 4. Similarly, the relationship can be expressed as follows:

$$
\mathrm{V}_{\text {inner }}=40.77 * \mathrm{M}_{\text {striking }}{ }^{-0.07} \text {-ln } \mathrm{M}_{\text {struck }}
$$

Study on the simulation results showed that: $\mathrm{V}_{\text {outer }}$ and $V_{\text {inner }}$ are inverse with $M_{\text {striking }}$ and $M_{\text {struck, }}$, and the drift velocity is inverse with $M_{\text {struck. }}$ It is analyzed that the ship drift velocity will affect the $V_{\text {outer }}$ and $V_{\text {inner }}$.

Therefore, this paper designed two experiments to verify the above two cases:

(1) 100000 ton ship at a velocity of $6 \mathrm{~m} / \mathrm{s}$ vertical collide with the different tonnage of struck ship;

(2) 100,000-ton ship at a velocity of $5 \mathrm{~m} / \mathrm{s}$ respectively vertical collide the 50,000-ton double-hull oil tanker which the cargo is constrained and the other is without constrained. 


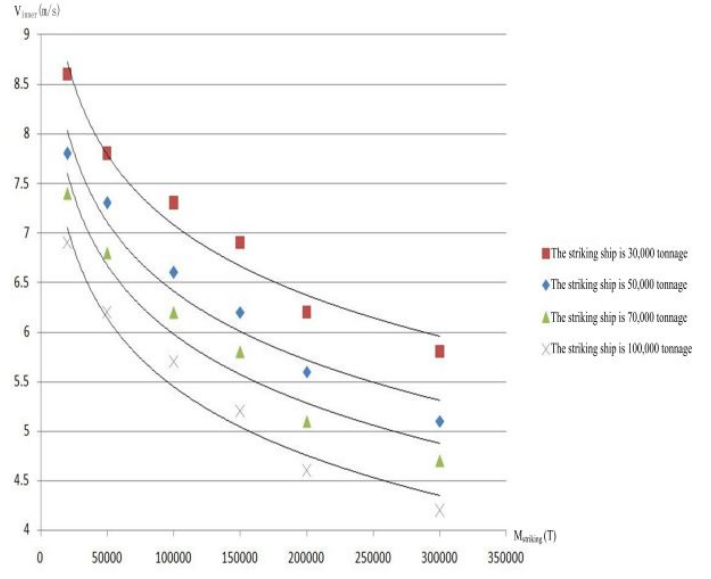

Figure 4. Curvilinear relation between $V_{\text {inner }}$ and $M_{\text {striking }} \& M_{\text {struck }}$

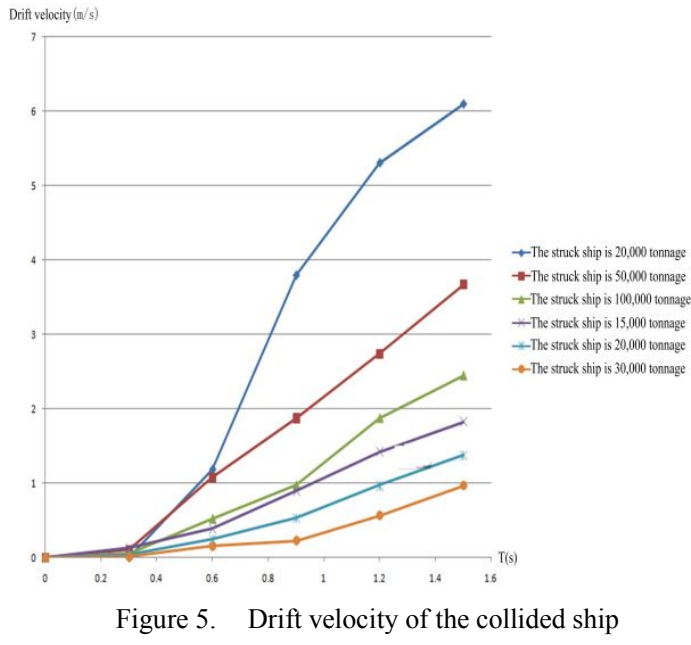

The one case simulation results can be shown in Figure 5 , we can see, the smaller of $M_{\text {struck }}$ the greater of the drift velocity, that's the reason of $\mathrm{V}_{\text {outer }}$ and $\mathrm{V}_{\text {inner }}$ are inverse with $\mathrm{M}_{\text {struck. }}$

Compared two kinds of collision force generated by the second case, as shown in Figure 6, can be seen from the figure:

(1) The collision force curve had two obvious unloading when the cargo was constrained, which represent the inner and outer shell rupture; however, when the cargo without constrained, the collision force curve only had one unloading, which represent the outer shell rupture.

(2) When the cargo was constrained that the time of the outer shell rupture was earlier than the cargo without constrained.

(3)When the cargo was constrained that the collision force was larger than the cargo without constrained, therefore the drift velocity of the struck ship which could "reduced" the collision force.

Figure 7 shows the damage of the inner shell, from the figure when the cargo was constrained the inner shell was ruptured, and when the cargo without constrained the inner shell only had buckling deformation but not broken, which also proves the above conclusions.
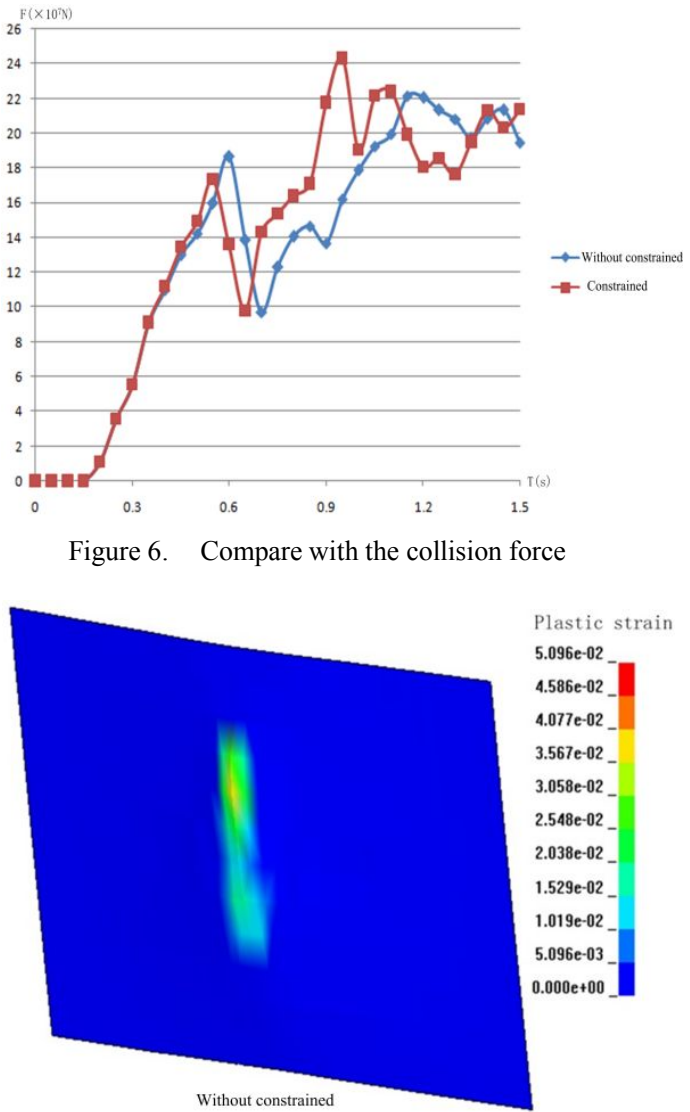

Plastic strain 5.096e-02 $4.586 \mathrm{e}-02$ 4.077e-02 $3.567 \mathrm{e}-02$ $3.058 \mathrm{e}-02$ $2.548 \mathrm{e}-02$ $2.038 \mathrm{e}-02$ $1.529 \mathrm{e}-02$ $1.019 \mathrm{e}-02$ $5.096 \mathrm{e}-03$ $0.000 e+00$

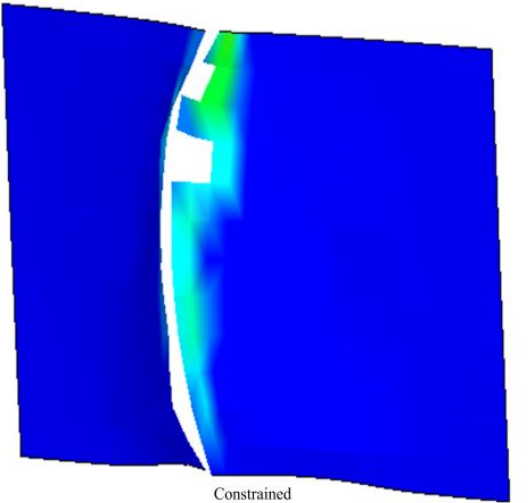

lastic strain $9.679 \mathrm{e}-02$ $8.711 \mathrm{e}-02$ $7.743 \mathrm{e}-02$ $6.775 \mathrm{e}-02$ 5.807e-02 $4.839 \mathrm{e}-02$ 3.872e-02 $2.904 \mathrm{e}-02$ $1.936 \mathrm{e}-02$ $9.679 \mathrm{e}-03$ $0.000 \mathrm{e}+00$

Figure 7. Compare with the deformation of inner shell

\section{CONCLUSIONS}

(1)The function of outer shell critical velocity of the striking ship is $\mathrm{V}_{\text {outer }}=44.37 * \mathrm{M}_{\text {striking }}{ }^{-0.08}-1.302 * \ln \mathrm{M}_{\text {struck }}$; and the function of inner critical velocity of the striking ship is $V_{\text {inner }}=40.77 * \mathrm{M}_{\text {striking }}{ }^{-0.07}$-ln $\mathrm{M}_{\text {struck. }}$.

(2)The tonnage of striking ship is inversely with $V_{\text {outer }}$ and $V_{\text {inner, }}$, which meas the striking ship tonnage is larger than the critical velocity is smaller.

(3)The tonnage of struck ship is inversely with $V_{\text {outer }}$ and $V_{\text {inner, }}$, which meas the struck ship tonnage is lighter that the critical velocity is bigger, the reason is that the struck ship tonnage is lighter that the drift velocity is bigger.

(4)Through this study, it can provide the theoretical basis for effective maritime control, control of the ship velocity in specific waters, to avoid oil tanker collision which may lead oil spill. In addition, for large oil tankers, we should pay more attention to supervision. 
TABLE III. MAIN DIMENSIONS AND PARAMETERS

\begin{tabular}{|c|c|c|c|c|c|c|c|}
\hline Ship type & Length & Breadth & $\begin{array}{l}\text { Load } \\
\text { draft }\end{array}$ & $\begin{array}{c}\text { Thickness of } \\
\text { Bow shell }\end{array}$ & $\begin{array}{l}\text { Distance of } \\
\text { double shell }\end{array}$ & $\begin{array}{l}\text { Thickness of outer } \\
\text { shell }\end{array}$ & $\begin{array}{c}\text { Thickness of } \\
\text { inner shell }\end{array}$ \\
\hline 10,000 tonnage bulk cargo ship & 150 & 20 & 8.5 & 16.5 & - & - & - \\
\hline 30,000 tonnage bulk cargo ship & 190 & 26 & 10.8 & 17.1 & - & - & - \\
\hline 50,000 tonnage bulk cargo ship & 230 & 32 & 12.7 & 17.7 & - & - & - \\
\hline 70,000 tonnage bulk cargo ship & 253 & 35 & 13,8 & 18.2 & - & - & - \\
\hline 100,000 tonnage bulk cargo ship & 260 & 39 & 15.2 & 19 & - & - & - \\
\hline 20,000 tonnage oil tanker & 182 & 25 & 10 & - & 1.5 & 12 & 12 \\
\hline 50,000 tonnage oil tanker & 235 & 32 & 12.6 & - & 1.8 & 13.5 & 13 \\
\hline 100,000 tonnage oil tanker & 268 & 39 & 15.2 & - & 2.1 & 15 & 14 \\
\hline 150,000 tonnage oil tanker & 294 & 46 & 17.7 & - & 2.4 & 17 & 15 \\
\hline 200,000 tonnage oil tanker & 326 & 50 & 19.1 & - & 2.7 & 18 & 17.5 \\
\hline 300,000 tonnage oil tanker & 358 & 56 & 22.4 & - & 3.0 & 20.5 & 19.5 \\
\hline
\end{tabular}

\section{ACKNOWLEDGMENT}

The present research was partly funded by Zhejiang Ocean University start research funding, NO. 21185011614.

\section{REFERENCES}

[1] HU Zhiqiang, Gao Zhen, GU Yongning. Research on the crashworthiness of a Y-shape side structure design for FPSO [J]. Journal of Shanghai Jiao tong University, 2013, 39(5):706-710.

[2] ZHANG Yanchang, YANG Daiyu ,WANG Zili. Effects of liquid cargo on side structure behaviors of a VLCC in collision [J]. Explosion and Shock Waves, 2010, 30(5):479-486.

[3] Li Song. Research and Analysis of the Ship's Buffer Bulbous Bow Structure [D].Wuhan:Wuhan University of Technology,2011.

[4] TABRI K, MAATTANEN J, RANTA J. Model-scale experiments of symmetric ship collision [J]. International Journal of Mar Sci Techno, 2008 13:71-48.

[5] FAN W, YUAN W C, FAN Q W. Calculation method of ship collision force on bridge using artificial neural network [J]. Journal of Zhejiang university-Science A(Applied Physics \& Engineering), 2012, 9(5):514-623.

[6] MA Jun, TAO Liang. Effect of initial velocity on structure of collided ship $[\mathrm{J}]$. Journal of Dalian University of Technology, 2010,48(1): 90-94.

[7] Seiichiro Yagi, Hideki Kumamoto, Osamu Muragishi, etc. A Study on collision buffer characteristic of sharp entrance angle bow structure [J]. Marine Structures, 2011, (22):12-23.

8] WANG Zili, GU Yongning. Influence of impact condition on behavior of double side structure in collision [J]. Ship Engineering, 2010, (6):13-16

[9] ZHANG Yanchang, LIU Kun, WANG Zili. Collision capability of side structure under different forms and stiffness of striking bows $[\mathrm{J}]$. Journal of Jiangsu University of Science and Technology (Natural Science Edition), 2010, 24(5):423-427.

[10] Ministry of Transport Maritime Bureau. Water accidents Monthly Statistics [R].1999-2014.

[11] JIANG Huatao, GU Yongning. Collision characteristics of the bow structure of tanker [J]. Journal of Shanghai Jiao tong University, 2013,37(7): 985-989.

[12] MINORSKY V U. An analysis of ship collision to protection of nuclear powered plant [J]. Journal of Ship Research, 1959, 3(2):1-

[13] WANG Zili, JIANG Zhiyong, GU Yongning. An add water mass model for numerical simulation of ship/ship collisions [J]. Explosion and Shock Waves, 2012, 22(4):321-326.

[14] ISSC (2006) Committee V.1: Collision and Grounding[C]. 16 ${ }^{\text {th }}$ International Ship and Offshore Structures Congress (ISSC), Southampton, UK, 20-25 August 2012.

[15] McDermott J F, Kline R G, Jones E, etc. Tanker structural analysis for minor collisions [J]. SNAME Transactions, 1974, 82:382-414

[16] Paik J K, Pedersen P T. Modeling of the internal mechanics in ship collisions [J]. Ocean Engineering, 1996, 23(2):107-142. 